\title{
Guideline-directed low-density lipoprotein management in high-risk ischemic stroke or transient ischemic attack admissions in China from 2015 to 2019
}

\author{
Hong-Qiu Gu ${ }^{1,2} \wedge$, Kai-Xuan Yang ${ }^{1,2}$, Xin Yang ${ }^{1,2}$, Chun-Juan Wang ${ }^{1,2}$, Tian-Jie Lyu ${ }^{1,2}$, Xing-Quan Zhao ${ }^{1,3}$, \\ Yi-Long Wang ${ }^{1,3}$, Li-Ping Liu ${ }^{1,4}$, Chelsea Liu ${ }^{5}$, Hao $\mathrm{Li}^{1}$, Yong Jiang ${ }^{1}$, Yong-Jun Wang ${ }^{1,2,3}, \mathrm{Zi}^{-X i a o ~} \mathrm{Li}^{1,2,3,6,7}$ \\ ${ }^{1}$ China National Clinical Research Center for Neurological Diseases, Beijing Tiantan Hospital, Capital Medical University, Beijing, China; ${ }^{2}$ National \\ Center for Healthcare Quality Management in Neurological Diseases, Beijing Tiantan Hospital, Capital Medical University, Beijing, China; \\ ${ }^{3}$ Vascular Neurology, Department of Neurology, Beijing Tiantan Hospital, Capital Medical University, Beijing, China; ${ }^{4}$ Neuro-intensive Care Unit, \\ Department of Neurology, Beijing Tiantan Hospital, Capital Medical University, Beijing, China; ${ }^{5}$ Department of Epidemiology, Harvard T.H. Chan \\ School of Public Health, Harvard University, Boston, MA, USA; ${ }^{6}$ Chinese Institute for Brain Research, Beijing, China; ${ }^{7}$ Research Unit of Artificial \\ Intelligence in Cerebrovascular Disease, Chinese Academy of Medical Sciences, Beijing, China \\ Contributions: (I) Conception and design: HQ Gu, ZX Li; (II) Administrative support: ZX Li, YJ Wang; (III) Provision of study materials or patients: \\ ZX Li, YJ Wang; (IV) Collection and assembly of data: X Yang, CJ Wang, Y Jiang; (V) Data analysis and interpretation: HQ Gu, KX Yang; (VI) \\ Manuscript writing: All authors; (VII) Final approval of manuscript: All authors. \\ Correspondence to: Yong-Jun Wang, MD. Department of Neurology, Beijing Tiantan Hospital, Capital Medical University, No. 119 West Road, \\ Southern Fourth Ring Road, Fengtai District, Beijing, China. Email: yongjunwang@ncrcnd.org.cn; Zi-Xiao Li, MD, PhD. Department of \\ Neurology, Beijing Tiantan Hospital, Capital Medical University, No. 119 West Road, Southern Fourth Ring Road, Fengtai District, Beijing, China; \\ Chinese Institute for Brain Research, Beijing, China. Email: lizixiao2008@hotmail.com.
}

Background: Lowering low-density lipoprotein cholesterol (LDL-C) is crucial for secondary stroke prevention in stroke patients with preexisting cardiovascular diseases (CVD) or cerebrovascular diseases (CeVD). However, data on attainment of guideline-recommended LDL-C levels are lacking.

Methods: We analyzed data from the Chinese Stroke Center Alliance (CSCA) program for patients with ischemic stroke and transient ischemic attack (TIA) hospitalized between August 2015 and July 2019. Participants were classified into different disease groups according to preexisting CeVD (stroke/TIA) or CVD [coronary heart disease (CHD) or myocardial infarction (MI)].

Results: Of 858,509 patients presenting with an acute stroke/TIA, 251,176 (29.3\%) had a preexisting CeVD, 44,158 (5.1\%) had preexisting CVD, 33,070 (3.9\%) had concomitant preexisting CeVD and CVD, and 530,105 (61.7\%) had no documented history of CeVD/CVD. Overall, only 397,596 (46.3\%) met the target for LDL-C <2.6 mmol/L, 128,177 (14.9\%) for LDL-C <1.8 mmol/L and 55,275 (6.4\%) for LDL-C $<1.4 \mathrm{mmol} / \mathrm{L}$, and patients with concomitant CeVD and CVD had higher attainment rates than other disease groups $(\mathrm{P}<0.001)$. Despite improvements over time in the proportion of patients who attain LDL-C targets ( $\mathrm{P}$ for trend $<0.05$ ), it remains suboptimal. Younger age, women, having a history of hypertension or dyslipidemia, current smoking or drinking, and being admitted to hospitals located in eastern China were associated with lower odds of meeting the LDL-C goals.

Conclusions: Overall attainment of guideline LDL-C targets in a population of stroke/TIA patients is low and indicates the need for better management of dyslipidemia, particularly for high-risk stroke patients with pre-existing CeVD or CVD.

Keywords: Lipids; cholesterol; ischemic stroke; guideline adherence; risk factors

^ ORCID: 0000-0003-1608-1856. 
Submitted Mar 26, 2021. Accepted for publication Jun 28, 2021.

doi: $10.21037 / \mathrm{atm}-21-1467$

View this article at: https://dx.doi.org/10.21037/atm-21-1467

\section{Introduction}

Stroke is a leading cause of death and disability globally, accounting for almost $5 \%$ of all disability-adjusted life-years and $10 \%$ of all deaths worldwide (1). China has the highest incidence and lifetime risk of stroke among all countries, and the burden is still increasing (2,3). Lowering low-density lipoprotein cholesterol (LDL-C) levels is an essential measure of stroke prevention (4), as evidence from clinical trials have shown that the LDL-C-lowering therapies can reduce the risk of major vascular events $(5,6)$. Scientific associations including the American Heart Association, American Stroke Association, American College of Cardiology, National Lipid Association, Chinese Stroke Association, European Society of Cardiology and European Atherosclerosis Society have established guidelines to reflect the importance of risk factor assessment and management, and most guidelines focus on LDL-C as the primary therapeutic target with LDL-C goals of $<2.6,<1.8$, or $<1.4 \mathrm{mmol} / \mathrm{L}$ depending on the risk level of the population (7-12).

Despite the well-established efficacy of lipid-lowering therapy, limited data are available on guideline attainment among high-risk stroke/TIA patients, such as those with a history of cerebrovascular diseases (CeVD; stroke and TIA) and cardiovascular diseases [CVD; coronary heart disease (CHD) and myocardial infarction (MI)]. Using data from the Chinese Stroke Center Alliance (CSCA), we aimed to evaluate the proportion and determinants of patients admitted with stroke/TIA meeting LDL-C guidelines, and conduct subgroup analyses among patients with different levels of risk based on their history of CeVDs and CVDs.

We present the following article in accordance with the STROBE reporting checklist (available at https://dx.doi. org/10.21037/atm-21-1467).

\section{Methods}

\section{Study cobort}

The CSCA is a national, hospital-based, multicenter, voluntary, multifaceted intervention and continuous quality improvement initiative. This program is made available to all Chinese secondary and tertiary hospitals. Details of the CSCA Program have been published previously (13).
In brief, patients were enrolled if they had a primary diagnosis of stroke/TIA and were then confirmed by brain CT or MRI. Hospitals were instructed to record data of patient demographics, medical history, medications before admission, diagnostic tests, treatment, and in-hospital outcomes. Data were collected via a web-based patient data collection and management tool, which subsequently checks for data quality to ensure that the reported data are complete and internally consistent.

The study was conducted in accordance with the Declaration of Helsinki (as revised in 2013). The study was approved by the ethics board of Beijing Tiantan Hospital (approval number: KY2018-061-02), and individual consent for this retrospective analysis was waived.

\section{Study population}

We evaluated all patients with acute ischemic stroke or TIA enrolled in the CSCA project from August 1, 2015, to July 31, 2019 for potential inclusion in our analysis. Patients with missing data on low-density lipoprotein and other relevant clinical information were excluded. We classified patients into the following groups: (I) patients with preexisting stroke/TIA (group CeVD); (II) patients with preexisting CHD/MI (group CVD); (III) patients with concomitant preexisting CVD and CeVD; and (IV) patients with no documented history of CeVD or CVD.

\section{Management measures}

The 2016 Chinese guidelines for the management of dyslipidemia in adults (11) and Chinese Stroke Association guidelines for clinical management of cerebrovascular disorders (12) recommended the same target LDL-C $(<2.6 \mathrm{mmol} / \mathrm{L})$ for patients with ischemic stroke or TIA and comorbid atherosclerosis. A lower target $(<1.8 \mathrm{mmol} / \mathrm{L})$ was recommended for high-risk patients to achieve maximal benefit. The latest guidelines for dyslipidemia management issued by the European Society of Cardiology and European Atherosclerosis Society recommended an LDL-C goal of $<1.4 \mathrm{mmol} / \mathrm{L}$ for very high-risk patients (9). In this study, we first assessed the attainment of the recommended level LDL-C $<2.6 \mathrm{mmol} / \mathrm{L}$ for the general stroke/TIA patient 


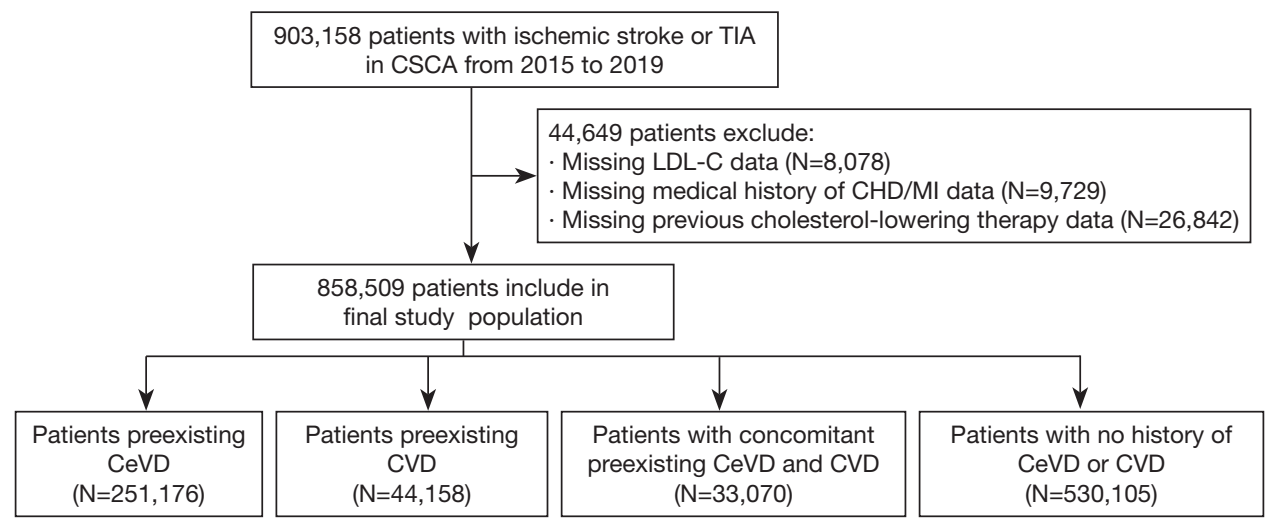

Figure 1 Study flow chart. TIA, transient ischemic attack; CSCA: the Chinese Stroke Association Alliance; CHD/MI, coronary heart disease or myocardial infarction; CeVD, cerebrovascular disease; CVD, cardiovascular disease; LDL-C, low-density lipoprotein cholesterol.

population and LDL-C $<1.8 \mathrm{mmol} / \mathrm{L}$ for high-risk patients at admission. In addition, we assessed the attainment of LDL-C $<1.4 \mathrm{mmol} / \mathrm{L}$ at admission and prescription of cholesterol-lowering agents at discharge.

\section{Statistical analysis}

Patients' baseline characteristics were described using frequencies and percentages for categorical variables and means and standard deviations (SD) for continuous variables. Due to the large sample size, we did not provide $\mathrm{P}$ values when comparing baseline characteristics across groups. Pearson chi-squared tests were used to test differences across the four patient groups for outcome measures. Temporal trends in meeting LDL-C targets were assessed using the Cochran Armitage trend test. Multivariable logistic regression models were performed to determine the independent predictors of meeting LDL-C targets, using the generalized estimating equations approach to account for within-hospital clustering. Covariates in the multivariable analysis included patient age, sex, medical history (hypertension, diabetes, dyslipidemia, atrial fibrillation, heart failure, PVD, smoking, drinking or stroke/TIA), medication history (antiplatelets, anticoagulants, antihypertensives, antihyperglycemics, or antihyperlipidemics) and hospital characteristics (hospital grade and geographical region). Medical history was selfreported disease prior to the index hospitalization, and medication history was defined as self-reported medication used from the index hospitalization up to 6 months ago.

SAS version 9.4 (SAS Institute, Cary, NC, USA) was used for all analyses. The macro \%ggBaseline was used to generate statistical tables (14). A value of $\mathrm{P}<0.05$ was considered statistically significant.

\section{Results}

A total of 903,158 patients presenting with an acute stroke/ TIA were initially enrolled. After excluding patients with missing data on low-density lipoprotein and other relevant clinical information, 858,509 patients were enrolled in the study (Figure 1). Of 858,509 patients with acute ischemic stroke or TIA, 251,176 (29.3\%) had preexisting CeVD, 44,158 (5.1\%) had preexisting CVD, 33,070 (3.9\%) had both, and 530,105 (61.7\%) had neither. Overall, the mean age (SD) was $66.0(12.0)$ years, and 324,402 (37.8\%) were women. A total of $62,094(7.2 \%)$ of patients were TIA, whereas the remaining $796,415(92.8 \%)$ were stroke (Table 1). The mean (SD) LDL-C was 2.76 (1.35), 2.70 (1.17), 2.70 (1.31), $2.85(1.19) \mathrm{mmol} / \mathrm{L}$ in patients in group CeVD, CVD, both CeVD and CVD, neither CeVD nor CVD, respectively (Figure 2).

\section{Characteristics}

Compared with other groups, especially with patients without a history of CeVD/CVD, patients with preexisting CeVD and CVD were older, more likely to have a history of hypertension, diabetes mellitus, dyslipidemia, atrial fibrillation, heart failure or peripheral vascular disorder, and were more likely to have a medication history of antiplatelets, anticoagulants, antihypertensives, 
Table 1 Baseline characteristics of patients with stroke or TIA by risk-groups

\begin{tabular}{|c|c|c|c|c|c|}
\hline Variables & Total $(\mathrm{N}=858,509)$ & $\begin{array}{l}\text { Preexisting CeVD } \\
\qquad(\mathrm{N}=251,176)\end{array}$ & $\begin{array}{l}\text { Preexisting CVD } \\
\qquad(\mathrm{N}=44,158)\end{array}$ & $\begin{array}{l}\text { Preexisting concomitant CeVD } \\
\text { and } \operatorname{CVD}(\mathrm{N}=33,070)\end{array}$ & $\begin{array}{l}\text { No history of CeVD/ } \\
\text { CVD }(N=530,105)\end{array}$ \\
\hline \multicolumn{6}{|l|}{ Demographic } \\
\hline Women & $324,402(37.8)$ & 90,070 (35.9) & $20,152(45.6)$ & $13,748(41.6)$ & $200,432(37.8)$ \\
\hline \multicolumn{6}{|l|}{ Medical history } \\
\hline Diabetes mellitus & $180,545(21.0)$ & $63,013(25.1)$ & $10,621(24.1)$ & $10,300(31.1)$ & $96,611(18.2)$ \\
\hline Dyslipidemia & 66,685 (7.8) & $36,183(14.4)$ & $2,758(6.2)$ & $6,732(20.4)$ & $21,012(4.0)$ \\
\hline Atrial fibrillation & $43,894(5.1)$ & $13,793(5.5)$ & 5,969 (13.5) & 4,836 (14.6) & $19,296(3.6)$ \\
\hline \multicolumn{6}{|l|}{ Index event } \\
\hline AIS & 796,415 (92.8) & 232,902 (92.7) & 40,733 (92.2) & $30,587(92.5)$ & $492,193(92.8)$ \\
\hline TIA & $62,094(7.2)$ & $18,274(7.3)$ & $3,425(7.8)$ & $2,483(7.5)$ & $37,912(7.2)$ \\
\hline \multicolumn{6}{|l|}{ Medication history } \\
\hline Antiplatelets & $184,896(21.5)$ & $112,020(44.6)$ & $12,087(27.4)$ & $17,679(53.5)$ & $43,110(8.1)$ \\
\hline Anticoagulants & $34,983(4.1)$ & $19,990(8.0)$ & $2,695(6.1)$ & 4,275 (12.9) & $8,023(1.5)$ \\
\hline Antihypertensives & $403,354(47.0)$ & $146,776(58.4)$ & $23,097(52.3)$ & 21,927 (66.3) & 211,554 (39.9) \\
\hline Tertiary & $523,961(61.0)$ & $145,915(58.1)$ & $27,446(62.2)$ & $18,996(57.4)$ & $331,604(62.6)$ \\
\hline \multicolumn{6}{|l|}{ Region } \\
\hline Eastern & $395,203(46.0)$ & $108,832(43.3)$ & $20,626(46.7)$ & $14,817(44.8)$ & 250,928 (47.3) \\
\hline Center & $288,835(33.6)$ & 92,839 (37.0) & $15,813(35.8)$ & $12,736(38.5)$ & $167,447(31.6)$ \\
\hline Western & $174,471(20.3)$ & 49,505 (19.7) & 7,719 (17.5) & $5,517(16.7)$ & $111,730(21.1)$ \\
\hline
\end{tabular}

CeVD, cerebrovascular disease; CVD, cardiovascular disease; PVD, peripheral vascular disorder; AIS, acute ischemic stroke; TIA, transient ischemic attack.

antihyperglycemics, or antihyperlipidemics (Table 1).

\section{Management measures}

Overall, 46.3\% ( $n=397,596)$ met the target for LDL-C $<2.6 \mathrm{mmol} / \mathrm{L}, 14.9 \%(\mathrm{n}=128,177)$ for LDL-C $<1.8 \mathrm{mmol} / \mathrm{L}$ and $6.4 \%(\mathrm{n}=55,275)$ for LDL-C $<1.4 \mathrm{mmol} / \mathrm{L}$. Although $33.1 \%(n=83,112)$ of patients with preexisting CeVD were receiving antihyperlipidemics at admission, only $49.7 \%$ $(\mathrm{n}=124,927)$ met the LDL-C $<2.6 \mathrm{mmol} / \mathrm{L}$ target, $17.9 \%$ $(\mathrm{n}=45,008)$ met the LDL-C $<1.8 \mathrm{mmol} / \mathrm{L}$ target, and $7.9 \%(\mathrm{n}=19,932)$ met the LDL-C $<1.4 \mathrm{mmol} / \mathrm{L}$ target. 


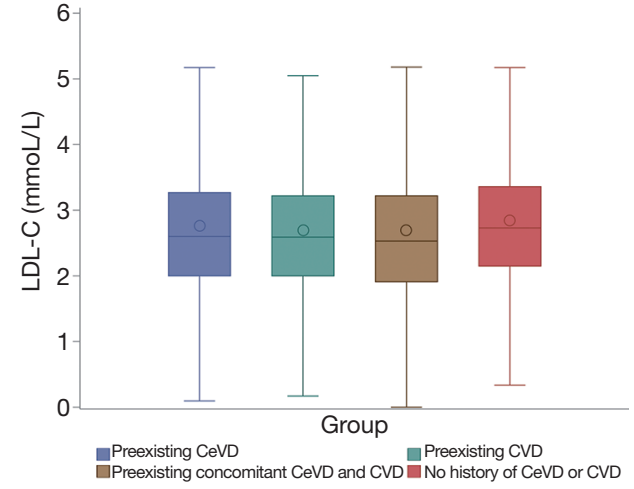

Figure 2 Box-plot representing low-density lipoprotein cholesterol (LDL-C) values on admission for each disease group. CeVD, cerebrovascular disease; CVD, cardiovascular disease; and LDL-C, low-density lipoprotein cholesterol.

Similarly, 17.6\% ( $\mathrm{n}=7,779)$ patients with preexisting CVD who were receiving antihyperlipidemics at admission, only $50.3 \%(\mathrm{n}=22,193), 17.4 \%(\mathrm{n}=7,676)$ and $7.6 \%(\mathrm{n}=3,349)$ met the LDL-C $<2.6 \mathrm{mmol} / \mathrm{L}, \mathrm{LDL}-\mathrm{C}<1.8 \mathrm{mmol} / \mathrm{L}$ and the $\mathrm{LDL}-\mathrm{C}<1.4 \mathrm{mmol} / \mathrm{L}$ targets, respectively. Among patients with preexisting concomitant CeVD and CVD, the proportion that met the LDL-C $<2.6 \mathrm{mmol} / \mathrm{L}, \mathrm{LDL}-\mathrm{C}$ $<1.8 \mathrm{mmol} / \mathrm{L}$ and $\mathrm{LDL}-\mathrm{C}<1.4 \mathrm{mmol} / \mathrm{L}$ targets were $52.5 \%, 20.7 \%$ and $9.2 \%$, respectively. Notably, nearly $90 \%$ of patients, overall and in each group, were discharged on statins after their index hospitalization (Table 2).

\section{Temporal trends}

We assessed the temporal trends in the proportion of patients meeting the LDL-C target from 2015 to 2019. Small increases over time were observed in the proportion that met the $\mathrm{LDL}-\mathrm{C}<1.8 \mathrm{mmol} / \mathrm{L}$ target among patients with preexisting $\mathrm{CeVD}$ (relative increase by $11.5 \%$, from $17.4 \%$ to $19.4 \%$ ), among patients with preexisting CVD (relative increase by $27.7 \%$, from $17.3 \%$ to $22.1 \%$ ), and among patients with preexisting concomitant $\mathrm{CeVD}$ and CVD (relative increase by $12.3 \%$, from $21.9 \%$ to $24.6 \%$ ), but not in patients without a medical history of $\mathrm{CeVD}$ or CVD (Figure 3 and Table 3).

\section{Factor associated with meeting $L D L-C$ targets}

Multivariable analysis using generalized estimating equations to account for within-hospital clustering showed that younger age, being female, having a history of hypertension or dyslipidemia, current smoking or drinking, and being admitted to hospitals located in eastern China were associated with lower odds of meeting the LDL-C goals. Atrial fibrillation, heart failure, and concomitant CeVD or CVD were associated with higher odds of achieving of LDL-C goals (Table 4).

\section{Discussion}

In this study of more than 850,000 patients with an acute ischemic stroke or TIA who were enrolled in CSCA, we evaluated attainment of guideline-recommended LDL-C targets in four different groups: patients with previous CeVD, CVD, both, and neither. We found that the attainment rates of guideline LDL-C targets in patients with stroke or TIA remain low. Overall, high-risk patients with concomitant preexisting CeVD and CVD were more likely to attain the LDL-C targets compared to other groups. We also identified independent factors associated with attainment to the LDL-C guidelines among high-risk patients, and found that younger age, being female, having a history of hypertension or dyslipidemia, currently smoking or drinking, and being admitted to hospitals located in eastern China were associated with lower odds of attaining the recommended LDL-C targets.

Large epidemiologic studies have shown that dyslipidemia is associated with an increased risk of unfavorable outcomes, and lower LDL-C levels are associated with lower rates of major coronary events (5,15-17). In accordance with these findings, most guidelines recommend lowering LDL-C to $2.6,1.8$ or $1.4 \mathrm{mmol} / \mathrm{L}$, or alternatively to achieve $\geq 50 \%$ LDL-C reduction from baseline. Our study provides an assessment of the efficacy of real-world clinical practice on guideline-based cholesterol management in high-risk ischemic stroke patients with concomitant preexisting CeVD or CVD. We observed significant gaps between recommendations from evidencebased medicine and data from real-world clinical practice.

In our study, significant gaps were found between guideline recommendations and real-world clinical practice. Previous studies also reported significant gaps between evidence-based medicine and real-world clinical practice (18-21). For example, in DYSIS II, only $29.4 \%$ of the patients attained the LDL-C target of $<1.8 \mathrm{mmol} / \mathrm{L}$ (22). In the French cohort from DYSIS II, $67.7 \%$ and $28.4 \%$ of the CHD patients attained the LDL-C targets of $<2.6$ and $<1.8 \mathrm{mmol} / \mathrm{L}$, respectively (23). The attainment rates to the recommended LDL-C targets in the CSCA program was 
Table 2 Attainment of guideline LDL-C targets by patient disease group

\begin{tabular}{|c|c|c|c|c|c|c|}
\hline Variables & $\begin{array}{c}\text { Total } \\
(\mathrm{N}=858,509)\end{array}$ & $\begin{array}{l}\text { Preexisting CeVD } \\
\qquad(\mathrm{N}=251,176)\end{array}$ & $\begin{array}{l}\text { Preexisting CVD } \\
\qquad(\mathrm{N}=44,158)\end{array}$ & $\begin{array}{l}\text { Preexisting concomitant } \\
\text { CeVD and CVD }(\mathrm{N}=33,070)\end{array}$ & $\begin{array}{l}\text { No history of CeVD/ } \\
\text { CVD }(\mathrm{N}=530,105)\end{array}$ & $P$ value \\
\hline \multicolumn{7}{|l|}{ LDL-C targets } \\
\hline$<1.8 \mathrm{mmol} / \mathrm{L}$ & 128,177 (14.9) & 45,008 (17.9) & $7,676(17.4)$ & $6,856(20.7)$ & 68,637 (12.9) & $<0.001$ \\
\hline
\end{tabular}

CeVD, cerebrovascular disease; CVD, cardiovascular disease; LDL-C, low-density lipoprotein cholesterol.
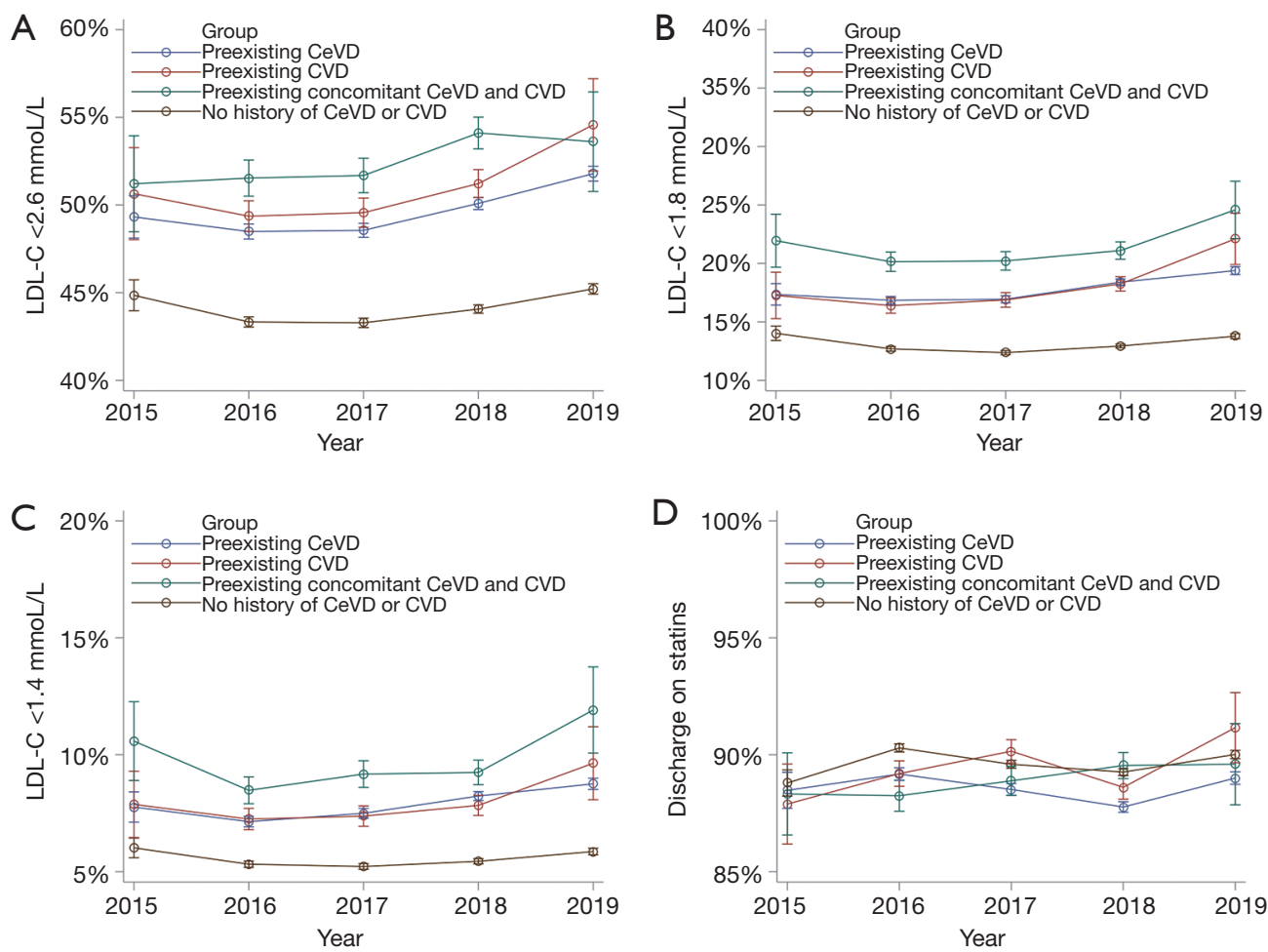

Figure 3 Temporal trend of attainment of LDL-C targets in CSCA program. (A) Trend of admission LDL-C $<2.6 \mathrm{mmol} / \mathrm{L}$ from 2015 to 2019 for each disease group; (B) trend of admission LDL-C $<1.8 \mathrm{mmol} / \mathrm{L}$ from 2015 to 2019 for each disease group; (C) trend of admission LDL-C <1.4 mmol/L from 2015 to 2019 for each disease group; (D) trend of discharge on statins from 2015 to 2019 for each disease group. CeVD, cerebrovascular disease; CVD, cardiovascular disease; LDL-C, low-density lipoprotein cholesterol.

lower than those in the Get-With-The-Guidelines-Stroke Registry several years ago with $51.3 \%$ for $<2.6 \mathrm{mmol} / \mathrm{L}$ and $19.8 \%$ for $<1.8 \mathrm{mmol} / \mathrm{L}$ (18). Encouragingly, however, temporal trend analysis showed there is an increasing trend for the attainment rates of LDL-C $<2.6 \mathrm{mmol} / \mathrm{L}$, LDL-C $<1.8 \mathrm{mmol} / \mathrm{L}, \mathrm{LDL}-\mathrm{C}<1.4 \mathrm{mmol} / \mathrm{L}$ and prescription of cholesterol-lowering agents at discharge, though the increase was only marginal. One possible reason was that highlevel evidence to support these guideline recommendations were not available until the release of results from the Treat Stroke to Target trial in 2020 (6).

Our study also showed that patients with history of CeVD or CVD were more likely to meet the LDL-C level recommended by the guidelines than other groups, 
Table 3 Temporal trends of attainment of guideline LDL-C targets among different risk groups

\begin{tabular}{|c|c|c|c|c|c|c|c|c|}
\hline Variables & $\begin{array}{c}\text { Total } \\
(\mathrm{N}=858,509)\end{array}$ & $\begin{array}{c}2015 \\
(\mathrm{~N}=21,504 \\
2.5 \%)\end{array}$ & $\begin{array}{c}2016 \\
(\mathrm{~N}=183,177 \\
21.3 \%)\end{array}$ & $\begin{array}{c}2017 \\
(\mathrm{~N}=214,133 \\
24.9 \%)\end{array}$ & $\begin{array}{c}2018 \\
(\mathrm{~N}=275,810 \\
32.1 \%)\end{array}$ & $\begin{array}{c}2019 \\
(\mathrm{~N}=163,885 \\
19.1 \%)\end{array}$ & $\begin{array}{l}\text { Relative } \\
\text { increase } \\
\text { rate (\%) }\end{array}$ & $\begin{array}{l}P \text { for } \\
\text { trend }\end{array}$ \\
\hline LDL-C $<2.6 \mathrm{mmol} / \mathrm{L}$ & $124,927(49.7)$ & $3,245(49.3)$ & $24,962(48.5)$ & $28,909(48.6)$ & $40,142(50.1)$ & $27,669(51.8)$ & 5.1 & $<0.0001$ \\
\hline LDL-C $<1.8 \mathrm{mmol} / \mathrm{L}$ & $45,008(17.9)$ & $1,142(17.4)$ & $8,673(16.8)$ & $10,086(16.9)$ & $14,748(18.4)$ & $10,359(19.4)$ & 11.5 & $<0.0001$ \\
\hline Discharged on statins & $222,328(88.5)$ & $5,822(88.5)$ & 45,908 (89.2) & $52,703(88.5)$ & $70,338(87.8)$ & $47,557(89.0)$ & 0.6 & 0.0207 \\
\hline \multicolumn{9}{|l|}{ Preexisting CVD } \\
\hline LDL-C $<2.6 \mathrm{mmol} / \mathrm{L}$ & $22,193(50.3)$ & $707(50.6)$ & $6,181(49.4)$ & $6,859(49.6)$ & $7,693(51.2)$ & $753(54.6)$ & 8.0 & 0.0002 \\
\hline \multicolumn{9}{|c|}{ Preexisting concomitant CeVD and CVD } \\
\hline LDL-C $<2.6 \mathrm{mmol} / \mathrm{L}$ & $17,375(52.5)$ & $658(51.2)$ & $4,679(51.5)$ & $5,120(51.7)$ & $6,279(54.1)$ & $639(53.6)$ & 4.7 & 0.0001 \\
\hline LDL-C $<1.8 \mathrm{mmol} / \mathrm{L}$ & $6,856(20.7)$ & $282(21.9)$ & $1,829(20.1)$ & $2,003(20.2)$ & $2,449(21.1)$ & $293(24.6)$ & 12.3 & 0.0265 \\
\hline LDL-C $<1.4 \mathrm{mmol} / \mathrm{L}$ & $3,030(9.2)$ & $136(10.6)$ & $770(8.5)$ & 909 (9.2) & $1,073(9.2)$ & $142(11.9)$ & 12.3 & 0.0456 \\
\hline Discharged on statins & 29,414 (88.9) & 1,135 (88.3) & 8,013 (88.2) & 8,806 (88.9) & $10,392(89.5)$ & 1,068 (89.6) & 1.5 & 0.0028 \\
\hline \multicolumn{9}{|l|}{ No history of CeVD/CVD } \\
\hline LDL-C $<2.6 \mathrm{mmol} / \mathrm{L}$ & $233,101(44.0)$ & $5,491(44.9)$ & 47,708 (43.3) & $56,636(43.3)$ & $74,490(44.1)$ & $48,776(45.2)$ & 0.7 & $<0.0001$ \\
\hline
\end{tabular}

CeVD, cerebrovascular disease; CVD, cardiovascular disease; LDL-C, low-density lipoprotein cholesterol.

indicating that patients with more vascular risk factors might pay more attention to their health management. Additionally, we found that patients with no history of CeVD or CVD had the lowest attainment rates. This suggests that clinicians should not overlook lipid management for low-risk populations. Consistent with previous studies $(22,24-26)$, our results showed that patients who are younger, female, have a history of hypertension or dyslipidemia, or are currently smoking or drinking had lower odds of attaining recommended LDL-C targets. More attention should be paid to these groups to improve their lipid management.

In Preexisting CeVD group, a higher proportion of anticoagulants use than that of atrial fibrillation were observed in our study. One possible reason is that self- reported medical history of atrial fibrillation was underreported. Another possible reason is, except for stroke patients with atrial fibrillation, stroke patients with other cardio-embolic reason (e.g., valvular heart disease, deep vein thrombosis, etc.) are recommend taking anticoagulants in clinical practice. The proportions of antihyperlipidemics use were higher than those of dyslipidemia in all groups. Two possible reasons may account for it. First, self-reported medical history of dyslipidemia was under-reported. Second, with the recognition ASCVD (atherosclerotic cardiovascular disease), patients with history of stroke/ TIA or CHD/MI would be recommend taking statins for prevention of stroke recurrence, according to the Chinese Stroke Association guidelines (27).

Our study has several limitations. First, participation 
Table 4 Factors associated with meeting different levels of LDL-C targets

\begin{tabular}{|c|c|c|c|}
\hline Variables & \multicolumn{3}{|c|}{ OR $(95 \% \mathrm{Cl})$} \\
\hline \multicolumn{4}{|l|}{ Demographics } \\
\hline Age, per $10 y$ & $1.09(1.08,1.10)$ & $1.09(1.08,1.10)$ & $1.07(1.05,1.09)$ \\
\hline Women (vs. men) & $0.70(0.69,0.71)$ & $0.72(0.70,0.73)$ & $0.74(0.72,0.76)$ \\
\hline Hypertension & $0.92(0.89,0.94)$ & $0.92(0.90,0.95)$ & $0.91(0.87,0.95)$ \\
\hline Diabetes mellitus & $0.93(0.90,0.95)$ & $1.04(1.01,1.08)$ & $1.13(1.08,1.18)$ \\
\hline Dyslipidemia & $0.59(0.56,0.62)$ & $0.66(0.62,0.69)$ & $0.67(0.63,0.71)$ \\
\hline Atrial fibrillation & $1.62(1.57,1.68)$ & $1.65(1.60,1.70)$ & $1.59(1.53,1.67)$ \\
\hline Current smoking & $0.93(0.91,0.95)$ & $0.88(0.85,0.90)$ & $0.84(0.80,0.87)$ \\
\hline Drinking & $0.97(0.94,1.00)$ & $0.98(0.95,1.01)$ & $0.98(0.94,1.03)$ \\
\hline \multicolumn{4}{|l|}{ Medication history } \\
\hline Antiplatelets & $1.15(1.11,1.20)$ & $1.18(1.13,1.23)$ & $1.20(1.14,1.26)$ \\
\hline Anticoagulants & $0.89(0.84,0.94)$ & $0.92(0.86,0.98)$ & $1.02(0.94,1.12)$ \\
\hline Antihypertensives & $1.06(1.03,1.09)$ & $1.07(1.04,1.11)$ & $1.07(1.03,1.11)$ \\
\hline Antihyperglycemics & $1.12(1.09,1.16)$ & $1.13(1.09,1.17)$ & $1.11(1.06,1.17)$ \\
\hline Antihyperlipidemics & $1.31(1.25,1.36)$ & $1.42(1.35,1.49)$ & $1.36(1.28,1.44)$ \\
\hline Preexisting concomitant CeVD and CVD & $1.21(1.15,1.27)$ & $1.36(1.29,1.43)$ & $1.33(1.25,1.42)$ \\
\hline Tertiary vs. secondary & $0.98(0.91,1.05)$ & $1.04(0.95,1.12)$ & $1.05(0.96,1.15)$ \\
\hline \multicolumn{4}{|l|}{ Region } \\
\hline Center vs. Western & $1.02(0.92,1.13)$ & $0.91(0.81,1.03)$ & $0.84(0.73,0.97)$ \\
\hline Eastern vs. Western & $0.84(0.77,0.92)$ & $0.75(0.68,0.83)$ & $0.67(0.59,0.76)$ \\
\hline
\end{tabular}

PVD, peripheral vascular disorder; CeVD indicates cerebrovascular disease; CVD, cardiovascular disease.

in CSCA was voluntary and this study did not have an elaborately designed sampling frame. The participating hospitals were more likely to be larger teaching hospitals with a strong interest in stroke care improvement. However, the large sample size and similar profile of patient characteristics to other registries may help improve the robustness and generalizability of our findings. Second,
LDL-C measurements were not performed in a central core laboratory. However, this reflects real-world practice where physicians initiate or titrate therapy based on available test results. Third, the database does not contain information on prestroke cholesterol drug class or dose, and therefore we could not assess LDL-C reduction relative to baseline values. Finally, we were not able to assess post-discharge 
lipid-lower drugs adherence and persistence or clinical outcomes since no follow-up data were collected.

\section{Conclusions}

The proportion of patients with stroke/TIA who meet the guideline targets for LDL-C are suboptimal for the overall population and for high-risk subgroups. At the time of admission, only 1 in 6 of stroke/TIA patients met the target for LDL-C $<1.8 \mathrm{mmol} / \mathrm{L}$, and less than half met the target for LDL-C $<2.6 \mathrm{mmol} / \mathrm{L}$. Although high-risk patients with concomitant preexisting stroke/TIA and CHD/MI were more likely to attain LDL-C targets, levels are still relatively low and may require intervention to improve management.

\section{Acknowledgments}

We thank all participating hospitals, physicians and nurses, and the Chinese Stroke Center Alliance Steering Committee members.

Funding: This work was supported by grants from the Ministry of Science and Technology of the People's Republic of China (National Key R\&D Program of China, 2017YFC1310901, 2016YFC0901002, 2017YFC1307905, 2015BAI12B00), Beijing Talents Project (2018A13, 2018000021223ZK03), CAMS Innovation Fund for Medical Sciences (2019-I2M-5-029), Beijing Municipal Committee of Science and Technology (Z201100005620010), and Beijing Natural Science Foundation (Z200016).

\section{Footnote}

Reporting Checklist: The authors have completed the STROBE reporting checklist. Available at https://dx.doi. org/10.21037/atm-21-1467

Data Sharing Statement: Available at https://dx.doi. org/10.21037/atm-21-1467

Conflicts of Interest: All authors have completed the ICMJE uniform disclosure form (available at https://dx.doi. org/10.21037/atm-21-1467). The authors have no conflicts of interest to declare.

Ethical Statement: The authors are accountable for all aspects of the work in ensuring that questions related to the accuracy or integrity of any part of the work are appropriately investigated and resolved. The study was conducted in accordance with the Declaration of Helsinki (as revised in 2013). The study was approved by the ethics board of Beijing Tiantan Hospital (approval number: KY2018-061-02), and individual consent for this retrospective analysis was waived.

Open Access Statement: This is an Open Access article distributed in accordance with the Creative Commons Attribution-NonCommercial-NoDerivs 4.0 International License (CC BY-NC-ND 4.0), which permits the noncommercial replication and distribution of the article with the strict proviso that no changes or edits are made and the original work is properly cited (including links to both the formal publication through the relevant DOI and the license). See: https://creativecommons.org/licenses/by-nc-nd/4.0/.

\section{References}

1. GBD 2016 Lifetime Risk of Stroke Collaborators; Feigin VL, Nguyen G, et al. Global, Regional, and CountrySpecific Lifetime Risks of Stroke, 1990 and 2016. N Engl J Med 2018;379:2429-37.

2. Krishnamurthi RV, Ikeda T, Feigin VL. Global, Regional and Country-Specific Burden of Ischaemic Stroke, Intracerebral Haemorrhage and Subarachnoid Haemorrhage: A Systematic Analysis of the Global Burden of Disease Study 2017. Neuroepidemiology 2020;54:171-9.

3. Wu S, Wu B, Liu M, et al. Stroke in China: advances and challenges in epidemiology, prevention, and management. Lancet Neurol 2019;18:394-405.

4. Isabel C, Calvet D, Mas JL. Stroke prevention. Presse Med 2016;45:e457-e471.

5. Amarenco P, Bogousslavsky J, Callahan A 3rd, et al. Highdose atorvastatin after stroke or transient ischemic attack. N Engl J Med 2006;355:549-59.

6. Amarenco P, Kim JS, Labreuche J, et al. A Comparison of Two LDL Cholesterol Targets after Ischemic Stroke. N Engl J Med 2020;382:9.

7. Kernan WN, Ovbiagele B, Black HR, et al. Guidelines for the prevention of stroke in patients with stroke and transient ischemic attack: a guideline for healthcare professionals from the American Heart Association/ American Stroke Association. Stroke 2014;45:2160-236.

8. O'Gara PT, Kushner FG, Ascheim DD, et al. 2013 ACCF/ AHA guideline for the management of ST-elevation myocardial infarction: executive summary: a report of the 


\section{Page 10 of 10}

American College of Cardiology Foundation/American Heart Association Task Force on Practice Guidelines. Circulation 2013;127:529-55.

9. Mach F, Baigent C, Catapano AL, et al. 2019 ESC/EAS Guidelines for the management of dyslipidaemias: lipid modification to reduce cardiovascular risk. Eur Heart J 2020;41:111-88.

10. Jacobson TA, Ito MK, Maki KC, et al. National lipid association recommendations for patient-centered management of dyslipidemia: part 1--full report. J Clin Lipidol 2015;9:129-69.

11. Chu J, Gao R, Zhao S, et al. 2016 Chinese Guideline for the management of dyslipidemia in adults. Chinese Circulation Journal 2016;31:937-53.

12. Association CS. Chinese Stroke Association guidelines for clinical management of cerebrovascular disorders. Beijing: People's Medical Publishing House, 2019.

13. Wang Y, Li Z, Wang Y, et al. Chinese Stroke Center Alliance: a national effort to improve healthcare quality for acute stroke and transient ischaemic attack: rationale, design and preliminary findings. Stroke Vasc Neurol 2018;3:256-62.

14. Gu HQ, Li DJ, Liu C, et al. \% ggBaseline: a SAS macro for analyzing and reporting baseline characteristics automatically in medical research. Ann Transl Med 2018;6:326.

15. Amarenco P, Goldstein LB, Szarek M, et al. Effects of intense low-density lipoprotein cholesterol reduction in patients with stroke or transient ischemic attack: the Stroke Prevention by Aggressive Reduction in Cholesterol Levels (SPARCL) trial. Stroke 2007;38:3198-204.

16. Castilla-Guerra L, Del Carmen Fernandez-Moreno M, Colmenero-Camacho MA. Statins in Stroke Prevention: Present and Future. Curr Pharm Des 2016;22:4638-44.

17. Silverman MG, Ference BA, Im K, et al. Association Between Lowering LDL-C and Cardiovascular Risk Reduction Among Different Therapeutic Interventions: A Systematic Review and Meta-analysis. JAMA 2016;316:1289-97.

18. Saposnik G, Fonarow GC, Pan W, et al. Guidelinedirected low-density lipoprotein management in high-risk patients with ischemic stroke: findings from Get with the Guidelines-Stroke 2003 to 2012. Stroke 2014;45:3343-51.

19. Teramoto T, Uno K, Miyoshi I, et al. Low-density lipoprotein cholesterol levels and lipid-modifying therapy prescription patterns in the real world: An analysis of more than 33,000 high cardiovascular risk patients in Japan.

\section{Gu et al. LDL management in ischemic strokes or TIA in China}

Atherosclerosis 2016;251:248-54.

20. Danchin N, Almahmeed W, Al-Rasadi K, et al. Achievement of low-density lipoprotein cholesterol goals in 18 countries outside Western Europe: The International ChoLesterol management Practice Study (ICLPS). Eur J Prev Cardiol 2018;25:1087-94.

21. Blom DJ, Raal F, Amod A, et al. Management of lowdensity lipoprotein cholesterol levels in South Africa: the International ChoLesterol management Practice Study (ICLPS). Cardiovasc J Afr 2019;30:15-23.

22. Gitt AK, Lautsch D, Ferrières J, et al. Cholesterol target value attainment and lipid-lowering therapy in patients with stable or acute coronary heart disease: Results from the Dyslipidemia International Study II. Atherosclerosis 2017;266:158-66.

23. Ferrières J, Rouyer MV, Lautsch D, et al. Suboptimal achievement of low-density lipoprotein cholesterol targets in French patients with coronary heart disease. Contemporary data from the DYSIS II ACS/CHD study. Arch Cardiovasc Dis 2017;110:167-78.

24. Ferrieres J, De Ferrari GM, Hermans MP, et al. Predictors of LDL-cholesterol target value attainment differ in acute and chronic coronary heart disease patients: Results from DYSIS II Europe. Eur J Prev Cardiol 2018;25:1966-76.

25. Gitt AK, Drexel H, Feely J, et al. Persistent lipid abnormalities in statin-treated patients and predictors of LDL-cholesterol goal achievement in clinical practice in Europe and Canada. Eur J Prev Cardiol 2012;19:221-30.

26. Chiang CE, Ferrières J, Gotcheva NN, et al. Suboptimal Control of Lipid Levels: Results from 29 Countries Participating in the Centralized Pan-Regional Surveys on the Undertreatment of Hypercholesterolaemia (CEPHEUS). J Atheroscler Thromb 2016;23:567-87.

27. Liu L, Chen W, Zhou H, et al. Chinese Stroke Association guidelines for clinical management of cerebrovascular disorders: executive summary and 2019 update of clinical management of ischaemic cerebrovascular diseases. Stroke Vasc Neurol 2020;5:159-76.

Cite this article as: Gu HQ, Yang KX, Yang X, Wang CJ, Lyu TJ, Zhao XQ, Wang YL, Liu LP, Liu C, Li H, Jiang Y, Wang YJ, Li ZX. Guideline-directed low-density lipoprotein management in high-risk ischemic stroke or transient ischemic attack admissions in China from 2015 to 2019. Ann Transl Med 2021;9(15):1224. doi: 10.21037/atm-21-1467 